\title{
Educação em saúde no esporte com crianças e jovens em condição de vulnerabilidade social
}

\section{Sports health education of socially vulnerable children and youth}

\section{Educación en salud en el deporte con niños y jóvenes en condiciones sociales vulnerables}

\author{
Ana Angélica Romeiro Cardoso (iD \\ Centro Universitário Estácio do Ceará - Fortaleza (CE) - Brasil
}

Maria Raquel da Silva Lima (iD

Centro Universitário Estácio do Ceará - Fortaleza (CE) - Brasil

Universidade de Fortaleza - Fortaleza (CE) - Brasil

Márcia Oliveira Coelho Campos (D)
Estratégia de Saúde da Família - Fortaleza (CE) - Brasil
Universidade Estadual do Ceará - Fortaleza (CE) - Brasil

\section{Érika César Alves Teixeira iD}

Centro Universitário Estácio do Ceará - Fortaleza (CE) - Brasil

Universidade Estadual do Ceará - Fortaleza (CE) - Brasil

\section{Juliana Soares Rodrigues Pinheiro iD}

Centro Universitário Estácio do Ceará - Fortaleza (CE) - Brasil

Universidade Estadual do Ceará - Fortaleza (CE) - Brasil

\section{RESUMO}

Objetivo: Relatar a experiência de universitários com atividades de educação em saúde no esporte com crianças e jovens em condições de vulnerabilidade social. Síntese dos dados: Trata-se de um relato de experiência que teve como base o desenvolvimento de atividades de educação em saúde realizada por universitários, para crianças e jovens na faixa etária de 7 a 23 anos, integrantes do projeto Areninha, localizado em um bairro periférico da cidade de Fortaleza, Ceará, Brasil. As atividades tiveram início em maio de 2018 e fim em novembro de 2019, com a realização de 11 encontros, sendo três atividades executadas pela preceptora e os acadêmicos da disciplina do estágio em saúde pública de um curso de nutrição de uma universidade privada. Os temas abordados foram: Bullying: uma partida de todos; Alimentação saudável; O açúcar por trás dos alimentos industrializados. Conclusão: Diante do que foi apresentado, conclui-se que a forma lúdica de abordar temas de educação em saúde fez alcançar de uma maneira ampla os objetivos das atividades, havendo uma excelente interação com os participantes, facilitando o entendimento deles pela simplicidade da explanação.

Descritores: Educação em Saúde; Promoção da Saúde; Esportes; Vulnerabilidade Social.

\section{ABSTRACT}

Objective: To report the experience of university students in conducting sports health education activities with socially vulnerable children and youth. Data Synthesis: This is an experience report based on health education activities carried out by university students with children and youth aged 7 to 23 years participating in the Areninha project, located in a peripheral neighborhood in the city of Fortaleza, Ceará, Brazil. The activities began in May 2018 and ended in November 2019. A total of 11 meetings were held, three of which were carried out by the preceptor and students of the public health internship of a nutrition school of a private university. The subjects addressed were: Bullying: a game for everyone; Healthy eating; The sugar in processed foods. Conclusion: In view of what has been presented herein, it is concluded that the playful way of addressing health education themes allowed achieving the goals of the activities in a broad way, with an excellent interaction with the participants, which facilitated understanding due to the simple nature of the explanation.

Descriptors: Health Education; Health Promotion; Sports; Social Vulnerability.

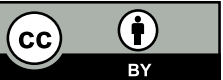




\section{RESUMEN}

Objetivo: Relatar la experiencia de universitarios con actividades de educación en salud en el deporte con niños y jóvenes en condiciones sociales vulnerables. Síntesis de los datos: Se trata de un relato de experiencia basado en el desarrollo de actividades de educación en salud realizada por universitarios para niños y jóvenes de la franja de edad entre 7 y 23 años integrantes del proyecto Areniña localizado en un barrio de la periferia de Fortaleza, Ceará, Brasil. Las actividades se iniciaron en mayo de 2018 hasta noviembre de 2019 con la realización de 11 encuentros con tres actividades realizadas por la tutora y los académicos de la disciplina de práctica en salud pública de un curso de nutrición de una universidad privada. Los temas abordados fueron: Bullying: un partido de todos; Alimentación saludable; El azúcar por detrás de los alimentos industrializados. Conclusión: Ante lo presentado se concluye que la forma lúdica de hablar de temas de educación en salud ha permitido el amplio alcance de los objetivos de las actividades con una interacción excelente de los participantes lo que ha facilitado su comprensión a partir de la simplicidad de la explanación.

Descriptores: Educación en Salud; Promoción de la Salud; Deportes; Vulnerabilidad Social.

\section{INTRODUÇÃO}

O esporte é conhecido como um dos fenômenos socioculturais mais importantes do final do século XX. Preserva marcantes ligações com inúmeras áreas essenciais para a raça humana, como saúde, educação e turismo, o que o atribui uma peculiaridade de caráter interdisciplinar ${ }^{(1)}$.

A atividade esportiva recreativa é uma forma comum de atividade física (AF) no tempo de lazer. Há indícios de que a participação em atividades esportivas é mais predominante entre os mais jovens, tendo início na infância, entre seis e 10 anos, com os meninos antecedendo as meninas. Verifica-se um decréscimo linear do número de componentes com o aumento da idade, em ambos os sexos ${ }^{(2)}$.

Segundo o Ministério do Esporte ${ }^{(3)}$, em 2013, o futebol recreativo era o principal esporte praticado pelos brasileiros $(59,8 \%)$, seguido de vôlei $(9,7 \%)$, natação $(4,9 \%)$ e futebol de salão ou futsal $(3,3 \%)$.

A prática esportiva é um instrumento imprescindível em territórios de vulnerabilidade social, e corrobora consideravelmente para que os participantes possam seguir uma rotina esportiva, respeitando regras e responsabilidades expostas a eles. Vulnerabilidade social é uma definição com várias dimensões que tem relação com uma situação de precariedade moral ou material, de pessoas ou grupos, frente à ameaças realizadas pela condição socioeconômica, envolvendo pessoas ou famílias que estão em processo de exclusão social(4). Dessa forma, um olhar voltado para essa população pode proporcionar uma oportunidade de sentir valorizada, sendo uma forma de oportunizar a inclusão social com mudanças nas perspectivas futuras de vida.

Considera-se também que o esporte contribui com o desenvolvimento das crianças, aumentando sua autoestima, possibilitando novas amizades, ganhando conhecimento, respeito e organização( ${ }^{(5,6)}$. Uma pesquisa(7) comparou a coordenação motora entre escolares que praticam educação física e outros jovens participantes de projetos esportivos e, como resultado, percebeu que os participantes do projeto apresentaram melhor coordenação e desempenho.

No Brasil, o futebol amador manifesta-se como uma forma de envolvimento de classes sociais vistas como "inferiores" por uma paixão que é nacional. Dessa paixão concretizada têm-se respostas positivas relativas à inclusão de crianças e adolescentes de comunidades vulneráveis ${ }^{(8)}$.

Programas que apresentam um caráter social envolvendo o esporte surgem constantemente. Na utilização dos espaços físicos participam pessoas capacitadas e responsáveis pela implantação de ações que vão além do esporte, como a promoção de hábitos de vida saudáveis, capacitações de cidadania, estímulo a um melhor desenvolvimento motor, ou seja, executam-se ações de educação em saúde ${ }^{(8,9)}$.

A educação em saúde pode ser definida como um processo educativo para promover a aquisição de cuidados sobre saúde, capacitando a população ${ }^{(10,11)}$ para novos conhecimentos e a adoção de modos favoráveis à saúde. Ela visa estimular a autonomia, proporcionando conhecimentos que façam o indivíduo saber cuidar de si e dos demais de seu convívio pessoal(12). Essa prática reúne tanto os profissionais da saúde que realizam as ações de promoção da saúde e prevenção de agravos, além da gestão que os apoiam, como a comunidade que recebe o aprendizado e se capacita(10,13).

Como base para as atividades referidas, remete-se o que preconiza a Política Nacional de Promoção da Saúde (PNPS), que visa proporcionar uma melhor qualidade de vida à população por meio da redução de situações de vulnerabilidade que possam impactar negativamente na sua saúde, como estilo de vida inadequado, condições de 
trabalho ruins, assim como a má alimentação, de modo que essa política visa a segurança alimentar e nutricional, auxiliando com intervenções e metas de redução da pobreza, inclusão social e cumprimento do direito humano à alimentação adequada ${ }^{(14)}$.

Tendo em vista a relevância do tema, e considerando que uma mudança de atitude possa contribuir positivamente para a promoção da saúde do público que participa de um projeto social, essa discussão se torna importante para garantir a melhoria da qualidade de vida da comunidade. Assim, este estudo apresenta como objetivo relatar a experiência de universitários com atividades de educação em saúde no esporte com crianças e jovens em condições de vulnerabilidade social.

\section{SÍNTESE DOS DADOS}

Trata-se de um relato de experiência que teve como base o desenvolvimento de atividades de educação em saúde direcionadas a crianças, adolescentes e adultos jovens, integrantes do projeto Areninha, localizado em um bairro na periferia da cidade Fortaleza, Ceará, Brasil. Segundo o site da Secretaria do Trabalho e Desenvolvimento Social, em uma postagem de 2017, o projeto veio para estimular uma nova proposta de cuidar das vulnerabilidades sociais das cidades, acreditando no esporte como meio de lazer e formação cidadã ${ }^{(15)}$.

O projeto esportivo em educação e saúde incluído nas Areninhas apresentou uma abordagem prática, didática, multiprofissional e interdisciplinar por meio de atividades educativas envolvendo profissionais da atenção básica do território, Corpo de Bombeiros do Ceará, Associação de Reciclagem Maravilha, acadêmicos e a preceptora da disciplina de estágio obrigatório em saúde pública do curso de Nutrição de uma universidade privada. Cada grupo ficou responsável por alguma atividade com os integrantes da Areninha, totalizando 11 encontros, dos quais três fizeram parte a preceptora e os alunos da referida universidade.

Pelo fato de a Areninha fazer parte da área de cobertura da Unidade de Atenção Primária à Saúde (UAPS), local do campo de estágio do curso de Nutrição da mencionada universidade, tornou-se local de interesse para a realização de atividades educativas. O interesse para a realização do estudo se deu durante o estágio supervisionado do curso de Nutrição, no qual surgiu a oportunidade de participação dos alunos na elaboração e execução do projeto de Educação em Saúde na Areninha de um bairro periférico da cidade de Fortaleza, Ceará, juntamente com a equipe da Estratégia Saúde da Família (ESF) e do Núcleo Ampliado de Saúde da Família e Atenção Básica (NASF-AB). A vivência no trabalho foi tão expressiva para os alunos que despertou a equipe para a realização do relato de experiência, podendo servir de exemplo para outras pessoas reproduzirem.

A proposta iniciou-se em maio de 2018 e teve seu final em novembro de 2019. As atividades adotadas pelo estágio foram sugeridas pelos próprios alunos após a preceptora responsável entregar a cada um deles uma folha em branco, na qual iriam escrever sugestões de temas a serem abordados, escolhendo-se os assuntos que tiveram maior pontuação e elencando-se os seguintes conteúdos: Bullying: uma partida para todos; Alimentação saudável; O açúcar por trás dos alimentos industrializados. Buscou-se utilizar o futebol não somente para incentivar a atividade física, mas como uma ferramenta de educação em saúde ${ }^{(16)}$.

\section{Bullying: uma partida para todos}

A palavra bullying deriva de "bully" que significa "brigão", "valentão". No Brasil, remete à intimidação(17). O bullying pode ser definido por atitudes agressivas entre pares, de maneira consciente e intencional, gerando impacto físico e/ou danos psicológicos ${ }^{(18,19)}$.

Estratégias de combate ao bullying constam na programação de projetos educacionais, pois critérios como punições socioeducativas, maior vigilância por parte da escola e reuniões com pais se apresentam como recursos insuficientes para proporcionar a transformação das atitudes dos envolvidos no processo ${ }^{(20)}$. O bullying ocorre não pela diferença propriamente dita, mas pelas imposições diante da cultura estabelecida pelas pessoas ${ }^{(21)}$. As principais pessoas afetadas pelo bullying são indivíduos que notadamente apresentam alguma característica diferente do padrão. Exemplos englobam a distinção entre gordo e magro, religiões, classes sociais, entre outros ${ }^{(22)}$.

A fim de combater ações de bullyng entre os jovens, surgiu, em fevereiro de 2016, uma lei federal para combater esse tipo de agressão nas escolas. A Lei n. ${ }^{\circ} 13.185 / 15$, com enfoque antibullying, busca conscientizar, prevenir e combater essa intimidação, seja física ou psicológica(23).

O primeiro conteúdo utilizado nessa experiência, intitulado Bullyng: uma partida para todos, iniciou com uma dinâmica de interação entre os alunos da Areninha, sendo trabalhado: deficiências visuais, motoras e a percepção de imagens. Os alunos formaram equipes a partir da junção de um quebra-cabeça. Em seguida, com as equipes já 
formadas, os universitários realizaram uma atividade com objetivo de todos desenharem um barco. Nessa primeira etapa, os alunos da Areninha não tinham limitações para o desenho e cada um ficou responsável por desenhar partes de um barco. Depois, adicionaram-se algumas dificuldades físicas, como venda nos olhos e amarração das mãos, a fim de mostrar as dificuldades que as pessoas podem apresentar ao conviver com outras pessoas, e fazê-los refletir.

Os jovens que apresentam deficiência são mais frágeis para se defender do bullying se comparadas a não deficientes ${ }^{(24)}$, sendo de relevância trabalhar constantemente e de maneira integral e intersetorial para evitar novos casos de bullying ${ }^{(25)}$. Pessoas com deficiência que praticam esportes apresentam grandes habilidades na forma particular de cada um para atuarem em um ambiente específico, sendo relevante desenvolver as percepções sensoriais para a prática da atividade ${ }^{(26)}$. As modificações realizadas para uma melhor inclusão dos deficientes ainda precisam de reforços, com maior inserção de políticas públicas nesse âmbito(27).

Em seguida, apresentaram-se aos alunos da Areninha cartazes com desenhos de diferentes imagens corporais e eles escolhiam uma, interpretando como se fosse uma pessoa que iria fazer parte do seu time em uma partida de futebol. Os cartazes consistiam em imagens de meninos: gordo, magro, alto, baixo e forte. Logo após a escolha, foi proposta uma reflexão sobre a percepção de imagem e os alunos relataram o motivo de suas escolhas.

A maioria excluiu o gordo, elegendo o magro, o alto e o forte, e justificaram essa última escolha por conseguir ter mais habilidade de corrida e não se cansar facilmente, havendo mais chance de ganhar a partida. Já o gordo receberia muitos apelidos ofensivos. A ação se encerrou com uma reflexão de que a exclusão do gordo e a insignificância do baixo se torna uma prática de bullying, devendo ser evitada por todos. A partir dos comentários dos alunos, os relatos foram avaliados como bola cheia (bom) e bola murcha (ruim). No jargão utilizado no futebol, utiliza-se "bola cheia" para o jogador muito bom, ou a condição em que ele se encontra, e "bola murcha" para o jogador muito ruim, ou em condição de desalento, arrefecimento em relação a outras pessoas.

Um estudo ${ }^{(28)}$ sobre bullying e inclusão a partir da visão de professores do ensino fundamental obteve relatos pessoais e de vivências. Quando questionados, um dos professores relatou ter sofrido bullying na adolescência por ter excesso de peso e que não conseguia jogar futebol, pois sofria com isso. Outro docente também relatou que, na divisão das atividades de sala, alguns alunos não gostavam de fazer tarefas com estudantes deficientes por preconceito.

Em pesquisa realizada com adolescentes estrangeiros em Portugal, a amostra (representativa) foi composta por 6.131 adolescentes que responderam a um questionário com perguntas que versavam sobre comportamentos, crenças e atitudes no âmbito da saúde. Os alunos sentiram-se importunados pelos colegas e disseram revidar de distintas formas. O estudo evidenciou que, quanto mais os alunos demonstravam que a escola era um ambiente inseguro, quanto mais denotavam insatisfação com a vida, mais eram vítimas de bullying e de agressores; o mesmo modelo é apurado com o porte de armas e para os consumos de álcool e droga. Concluíram que o bullying é um problema grave nas escolas por todo o mundo, de modo que representa um tema que precisam ter como pauta relevante na escola e recomendam que os resultados do estudo alertem estudantes, professores e gestores de educação(29).

\section{Alimentação saudável}

Em outra atividade, tratou-se da alimentação saudável com os alunos da Areninha. A educação alimentar e nutricional (EAN) pode ser referida como um campo de conhecimento e prática contínua, permanente, intersetorial e multiprofissional, que utiliza várias abordagens educacionais no âmbito dos conhecimentos relacionados à nutrição e à alimentação. As ações de EAN abrangem indivíduos ao longo de todo o curso da vida, grupos populacionais e comunidades, considerando as relações e significados que compõem o comportamento alimentar ${ }^{(30)}$.

Essa atividade contempla essa vertente da promoção da saúde. Na atividade da alimentação saudável, elaborouse um circuito da saúde com três estações:

Estação 1 Produziu-se um semáforo nutricional com papel nas cores verde (alimentos que devemos preferir), amarela (alimentos que devemos comer às vezes) e vermelho (alimentos que se deve evitar), representando, respectivamente, os alimentos in natura ou minimamente processados, os alimentos processados e os ultraprocessados. A partir daí, os participantes escolheram fotos de alimentos e colocaram onde eles acharam que deveriam estar. De acordo com o novo Guia Alimentar para a População Brasileira, são definidas as categorias de alimentos de acordo com o tipo de processamento empregado na sua produção, sendo usadas as citadas acima: in natura ou minimamente processados, processados e ultraprocessados ${ }^{(31)}$.

Em uma intervenção ${ }^{(32)}$ realizada para a promoção de hábitos saudáveis com 18 crianças em Pernambuco, Recife, Brasil, se utilizou a dinâmica do semáforo como atividade de educação nutricional. A maioria dos estudantes 
escolheu corretamente a cor do semáforo em relação aos alimentos, explicando porque optaram pela cor. Ainda enfatizaram relatar em casa o que aprenderam, pretendendo colocar em prática os bons hábitos alimentares.

Estação 2 - O consumo alimentar é um dos determinantes da saúde, de maneira que as intervenções de natureza educativa destacam-se, constituindo uma estratégia importante das políticas de saúde de abrangência global ${ }^{(33)}$. Foram exibidos alguns rótulos de alimentos do tipo pão integral, alimento achocolatado e biscoito recheado, e os participantes marcaram com um $(X)$ o que para eles seria um alimento não saudável e com um (OK) os saudáveis, despontando como uma ferramenta para a redução da obesidade e das doenças crônicas não transmissíveis (DCNT) ${ }^{(34)}$.

As informações explanadas na rotulagem nutricional servem de orientação e direcionamento no momento da compra, promovendo saúde e evitando a aquisição de insumos promotores de possíveis agravos, ricos em açúcares, sódio e gorduras, causadores das $\mathrm{DCNT}^{(33)}$.

Um estudo ${ }^{(3)}$ investigou escolhas alimentares de atletas em uma competição da Austrália, vinculando isso a orientações nutricionais prévias e à rotulagem nutricional. Havia 81 atletas, de 24 esportes e 58 países. A maioria dos atletas escolheu corretamente a quantidade de macronutrientes, porém $80,2 \%$ não consumiam frutas e $65,4 \%$ não tinham laticínios. A maior parte não utilizou a leitura dos rótulos para se direcionar, fato que pode ser relevante principalmente para portadores de alergias e intolerâncias alimentares. Para os atletas, por ser um público que constantemente se alimenta em ambientes diferentes, com culturas diferentes e vastas opções alimentares, torna-se difícil controlar a ingestão e fazer sempre boas escolhas ${ }^{(36)}$. Dessa forma, reflete a importância de uma educação nutricional efetiva para esse público.

Estação 3 - Nessa estação, explanou-se a importância de uma correta ingestão hídrica, principalmente no esporte, e o cálculo de água para saber a quantidade de consumo necessária diariamente para cada um. Recomenda-se que a ingestão hídrica deva ser em torno de 30 a $40 \mathrm{ml}$ água/kg peso por $\mathrm{dia}^{(37)}$.

$\mathrm{O}$ estado de desidratação deriva de uma relevante perda de líquidos corporais ${ }^{(38)}$. Uma pesquisa ${ }^{(39)}$ analisou a influência da desidratação na tomada de decisão em atletas participantes de campeonato brasileiro de futebol. Participaram 40 jogadores, entre 18 e 30 anos. Após a partida, aplicou-se um instrumento de Avaliação de Desempenho de Jogos. Os resultados mostraram uma redução efetiva do índice de tomada de decisão na condição de desidratação, influenciando seus passes, percepção, antecipação e, consequentemente, o desempenho final no jogo. Porém praticantes de esporte coletivo não podem hidratar-se bebendo água de qualquer forma, pois 0 excesso também ocasiona prejuízos, como a perda de eletrólitos ${ }^{(40)}$, daí a importância de uma correta orientação.

O circuito de estações proposto trouxe um aprendizado bastante dinâmico e participativo. A partir das informações oferecidas a cada etapa, percebeu-se a admiração dos participantes diante das descobertas de sua alimentação pouco variada e rica em industrializados que fariam mal à sua saúde. As crianças e jovens citaram exemplos do consumo errado por familiares que apresentam patologias, como diabetes e hipercolesterolemia. Com a posse do conhecimento, eles relataram que iriam ensinar em casa, o que proporcionou enorme satisfação aos acadêmicos de Nutrição, por terem tornado o público-alvo multiplicador de conhecimentos.

\section{O açúcar por trás dos alimentos industrializados}

A atividade sobre o açúcar por trás dos alimentos industrializados se realizou a partir do cálculo para demonstrar a quantidade de açúcar presente nos alimentos industrializados. Iniciou-se com uma explicação de educação nutricional, relacionando os riscos à saúde ao consumo diário e/ou exagerado do açúcar simples, escondido em alimentos. É fácil ultrapassar o limite saudável recomendado de açúcar quando não se sabe quanto desse componente está oculto nos alimentos processados.

Para tanto, foram selecionados alguns produtos comuns no cotidiano dos participantes e que contém alta quantidade de açúcares. Apresentaram-se aos alunos da Areninha os alimentos do tipo: refrigerante, biscoito waffers, leite condensado, cereal matinal, suco em pó e achocolatado, além de recipientes contendo açúcar e previamente mensurados com as quantidades exatas dos alimentos citados.

A Organização Mundial de Saúde ${ }^{(41)}$ determinou que o consumo máximo de açúcar para adultos e crianças deve ser menor que $5 \%$ do valor energético total da dieta. Como forma de orientar a população brasileira acerca dos melhores alimentos, o Guia Alimentar para a População Brasileira ${ }^{(31}$ afirma que a ingestão de açúcares deverá ocorrer em pequenas quantidades, dando preferência aos alimentos in natura, como frutas, verduras e hortaliças, e um menor consumo de alimentos industrializados, pois são ricos em aditivos e conservantes, podendo causar riscos à saúde. A Sociedade Brasileira de Pediatria confirma as orientações, enfatizando que é primordial optar por frutas ao invés de sucos (ricos em frutose e glicose), principalmente refresco em pó, que são repletos de açúcares, e refrigerantes ${ }^{(42)}$. 
Uma pesquisa analisou ${ }^{(43)}$ a influência da educação nutricional no consumo de açúcar de 51 escolares entre oito e 10 anos, com aplicação de questionários para avaliar os hábitos antes e depois de oficinas educativas. Constatou-se redução no consumo de refrigerantes, pães, biscoitos e maior ingestão de frutas, sendo considerável a atividade como proposta educativa, necessitando ser executada constantemente para uma melhor formação de bons hábitos. Por meio da educação nutricional, indivíduos capacitados possuem maior probabilidades de promover saúde.

A exposição visual de açúcar em porções quantitativas informada nos rótulos dos produtos industrializados apresentados deixou os participantes reflexivos diante da quantidade de açúcar existente em um produto que era consumido por eles diariamente. Para os acadêmicos de Nutrição, veio a sensação de missão cumprida, pois conseguiram fazer com que os participantes entendessem a importância de uma alimentação equilibrada e saudável, com baixa ingestão de carboidratos simples.

Apresentando como base a Política Nacional de Promoção da Saúde, este relato mostrou o desenvolvimento da igualdade e da maneira de viver, expandindo a capacidade da saúde individual e coletiva, e diminuindo vulnerabilidades e riscos à saúde resultantes dos determinantes sociais, econômicos, políticos, culturais e ambientais ${ }^{(14)}$.

Com o objetivo de partilhar o conhecimento, percebeu-se que a melhor forma foi a didática visual, simples e de fácil entendimento, que provocou uma grande interação no momento da realização das ações. Compreendeu-se que é possível a execução dessas estratégias em grupos e/ou projetos multidisciplinares, sendo o maior desafio disseminar projetos como este, seja por logística, articulação, seja até mesmo pela preferência de muitos profissionais pelo modelo individualizado de atendimento. Portanto, sugere-se que ações como estas sejam propagadas com maior frequência, principalmente em ambientes vulneráveis, sendo uma experiência transformadora na saúde coletiva.

\section{CONCLUSÃO}

Diante do apresentado, conclui-se que a forma lúdica de abordar temas de educação em saúde proporciona alcançar de maneira ampla o objetivo das atividades, havendo uma excelente interação com os jovens, pois facilita o entendimento deles pela simplicidade da explanação.

A participação de estudantes do curso de Nutrição favoreceu a troca de experiências entre os profissionais da unidade de saúde, bem como o intercâmbio de novas ideias, conceitos, planos e estratégias voltadas para a promoção da saúde, demonstrando a importância da participação dos profissionais de saúde não somente no binômio "profissional de saúde e atendimento", mas também no engajamento social.

\section{CONFLITOS DE INTERESSE}

Não há conflitos de interesses.

\section{CONTRIBUIÇÕES}

Ana Angélica Romeiro Cardoso contribuiu com a elaboração e delineamento do estudo. Maria Raquel da Silva Lima, Juliana Soares Rodrigues Pinheiro e Erika César Alves Teixeira contribuíram com a aquisição, análise e interpretação dos dados. Márcia Oliveira Coelho Campos contribuiu com a redação e/ou revisão do manuscrito.

\section{REFERÊNCIAS}

1. Tubino M. O que é esporte? São Paulo: Brasiliense; 1999.

2. Biernat $E$, Buchholtz $S$. The regularities in insufficient leisure-time physical activity in Poland. Int $J$ Environ Re Public Health [Internet]. 2016 [acesso em 2019 Jun 25];13(8):798. Disponível em: www.mdpi.com/16604601/13/8/798

3. Ministério da Cidadania (BR). Diesporte: diagnóstico nacional do esporte: o perfil do sujeito praticante ou não de esportes e atividades físicas da população brasileira [Internet]. Brasília: Ministério do Esporte; 2016 [acesso em 2019 Dez 29]. Disponível em: http://www.esporte.gov.br/diesporte/diesporte_revista_2016.pdf

4. Monteiro SRRP. O marco conceitual da vulnerabilidade social. Soc Debate [Internet]. 2011 [acesso em 2020 Ago 16];17(2):29-40. Disponível em: http://www.rle.ucpel.edu.br/index.php/rsd/article/view/695

5. Tolazzi T. Área de vulnerabilidade social: o futebol como uma possibilidade de transformação [trabalho de conclusão de curso] [Internet]. Santa Rosa: Universidade Regional do Noroeste do Estado do Rio 
Grande do Sul; 2015 [acesso em 2020 Jan 06]. Disponível em: http://bibliodigital.unijui.edu.br:8080/xmlui/ handle/123456789/3383

6. Pontes SS, Silva AM, Santos LMS, Sousa BVN, Oliveira EF. Práticas de atividade física e esporte no Brasil. Rev Bras Promoç Saúde [Internet]. 2019 [acesso em 2019 Set 23];32:8406. Disponível em: http://www. periodicos.unifor.br/RBPS/article/view/8406

7. Silva AS, Zampier JELC. Efeito da prática esportiva sistematizada no desempenho coordenativo com bola de escolares. Rev Bras Ciênc Mov [Internet]. 2018 [acesso em 2019 Out 02];26(3):134-40. Disponível em: https://portalrevistas.ucb.br/index.php/RBCM/article/view/7783

8. Castro CM, Cadete MMM. Da origem e história do futebol no Brasil ao futebol amador em comunidade de vulnerabilidade social: uma incursão na literatura. Caribeña Cienc Soc [Internet]. 2019 [acesso em 2020 Jan 06]. Disponível em: https://www.eumed.net/rev/caribe/2019/04/origem-futebol-brasil.html

9. Teixeira FC, Kravhychyn C, Barbosa-Rinalde IP, Oliveira AAB. Desenvolvimento de um projeto social esportivo: um relato de experiência no âmbito do Programa Segundo Tempo. Rev Corpoconsciência [Internet]. 2015 [acesso em 2019 Maio 26];19(1):22-32. Disponível: http://www.periodicoscientificos.ufmt.br/ ojs/index.php/corpoconsciencia/article/view/3794

10. Guimarães CGM, Silva SA, Zampier JELC. Visão dos pais sobre a participação de seus filhos em um programa esportivo social. Cad Educ Fis Esp [Internet]. 2019 [acesso em 2020 Jan 10];17(2):133-41. Disponível em: http://e-revista.unioeste.br/index.php/cadernoedfisica/article/view/16182

11. Ministério da Saúde (BR), Secretaria de Gestão do Trabalho e da Educação na Saúde. Glossário temático: gestão do trabalho e da educação na saúde [Internet]. $2^{\mathrm{a}}$ ed. Brasília: Ministério da Saúde; 2012 [acesso em 2020 Maio 20]. Disponível em: http://bvsms.saude.gov.br/bvs/publicacoes/glossario_tematico_gestao_ trabalho_educacao_saude_2ed.pdf

12. Machado MFAS, Monteiro EMLM, Queiroz DT, Vieira NFC, Barroso MGT. Integralidade, formação de saúde, educação em saúde e as propostas do SUS: uma revisão conceitual. Ciênc Saude Colet [Internet]. 2007 [acesso em 2019 Jun 11];12(2):335-42. Disponível em: https://www.scielosp.org/article/csc/2007.v12n2/335-342/

13. Falkenberg MB, Mendes TPL, Moraes EP, Souza EM. Educação em saúde e educação na saúde: conceitos e implicações para a saúde coletiva. Ciênc Saude Colet [Internet]. 2014 [acesso em 2020 Jan 27];19:847-52. Disponível em: https://www.scielosp.org/article/csc/2014.v19n3/847-852

14. Ministério da Saúde (BR). Política Nacional de Promoção da Saúde: PNPS: Anexo I da Portaria de Consolidação $n^{\circ} 2$, de 28 de setembro de 2017, que consolida as normas sobre as políticas nacionais de saúde do SUS [Internet]. Brasília: Ministério da Saúde, 2018 [acesso em 2020 Ago 16]. Disponível em: http:// bvsms.saude.gov.br/bvs/publicacoes/politica_nacional_promocao_saude.pdf

15. Governo do Estado do Ceará. STDS expõe projeto das Areninhas a 31 prefeituras municipais [Internet]. Fortaleza: Governo do Estado; 2017 [acesso em 02 Dez 2019]. Disponível em: https://www.ceara.gov. br/2017/03/23/stds-expoe-projeto-das-areninhas-31-prefeituras-municipais/

16. Del Vecchio F, Calonego C, Ribeiro Y. O futebol como meio de educação em saúde e atividade física para Jovens escolares [Internet]. In: Anais do 31ª Seminário de Extensão Universidade da Região Sul; 2014 Jun 1-21; Florianopólis. Florianopólis: UFSC; 2014 [acesso em 2020 Jan 02]. Disponível em: https://repositorio. ufsc.br/bitstream/handle/123456789/117272

17. Smith PK, Cowie H, Olafsson R F, Liefooghe AP. Definitions of bullying: a comparison of terms used, and age and gender differences, in a Fourteen-Country international comparison. Child Dev [Internet]. 2002 [acesso em 2019 Fev 15];73(4):1119-33. Disponível em: https://srcd.onlinelibrary.wiley.com/doi/abs/10.1111/14678624.00461

18. Olweus D. Annotation: bullying at school: basic facts and effects of a school- based intervention program. J Child Psychol Psychiatry [Internet]. 1994 [acesso em 2019 Fev 25];35(7):1171-90. Disponível em: https:// onlinelibrary.wiley.com/doi/abs/10.1111/j.1469-7610.1994.tb01229.x

19. Sullivan K. The anti-bullying handbook. Oxford: Oxford University Press; 2015.

20. Silva ABB. Bullying: mentes perigosas nas escolas. Rio de Janeiro: Fontanar; 2018. 
21. Borges AKS, Dellazzana-Zanon LL. Bullying e inclusão no ensino fundamental I: ações de professores. Rev Educ Espec Santa Maria [Internet]. 2019 [acesso em 2019 Maio 22];32:1-18. Disponível em: https:// periodicos.ufsm.br/educacaoespecial/article/view/31773

22. Araújo KH, Nepomuceno KR. A responsabilidade civil das instituições de ensino privadas nos casos de bullying entre alunos. Rev Fac Dir [Internet]. 2015 [acesso em 2019 Fev 24];36(2):53-9. Disponível em: http:// www.revistadireito.ufc.br/index.php/revdir/article/view/46

23. Presidência da República (BR). Lei no 13.185, de 6 de novembro de 2015. Institui o Programa de Combate à Intimidação Sistemática (Bullying). Brasília: Presidência da República; 2015 [acesso em 2020 Jan 02]. Disponível em: http://www.planalto.gov.br/ccivil_03/_ato2015- 2 018/2015/lei//13185.html

24. Castro ECVMD. Concepções e práticas de professores frente a situações de bullying contra crianças com deficiência intelectual: um estudo exploratório [dissertação] [Internet]. Brasília: Universidade Católica de Brasília; 2012 [acesso em 2020 Jan 06]. Disponível em: https://bdtd.ucb.br:8443/jspui/handle/123456789/692

25. Borsa JC, Petrucci GW, Koller SH. Parent participation in researches on school bullying. Psicol Esc Educ [Internet]. 2015 [acesso em 2020 Jan 16];19(1):41-8. Disponível em: https://www.scielo.br/scielo. php?pid=S1413-85572015000100041\&script=sci_arttext

26. Hockey J, Allen-Collinson J. Grasping the phenomenology of sporting bodies. Int Rev Sociol Sport [Internet]. 2007 [acesso em 2020 Fev 20];42(2):115-31. Disponível em: https://journals.sagepub.com/doi/ abs/10.1177/1012690207084747

27. Melo CH, Almeida JL Neto, Maranhão T, Souza F. Os desafios da inclusão de pessoas com deficiência no mercado de trabalho: um estudo multicaso no segmento atacadista alimentício na cidade de BarbalhaCE. Rev Psicol [Internet]. 2017 [acesso em 2019 Dez 19];11(37):572-98. Disponível em: https://idonline. emnuvens.com.br/id/article/view/861

28. Borges AKS. Bullying e inclusão no ensino fundamental I: concepções de professores [dissertação] [Internet]. Campinas: PUC; 2018 [acesso em 2020 Maio 20]. Disponível em: http://tede.bibliotecadigital.puc-campinas. edu.br:8080/jspui/bitstream/tede/1091/2/ANNA\%20KAROLINA\%20SANTORO\%20BORGES.pdf

29. Matos MG, Gonçalves A, Gaspar T. Adolescentes estrangeiros em Portugal: uma questões de Saúde. Psicol Saúde Doenças [Internet]. 2004 [acesso em 2020 Maio 20];5(1):75-85. Disponível em: http://www.scielo.oces. mctes.pt/pdf/psd/v5n1/v5n1a05.pdf

30. Ministério do Desenvolvimento Social e Combate à Fome (BR). Marco de referência de educação alimentar e nutricional para as políticas públicas [Internet]. Brasília: Secretaria Nacional de Segurança Alimentar e Nutricional; 2012 [acesso em 2020 Mai 20]. Disponível em: https://www.cfn.org.br/wp-content/ uploads/2017/03/marco_EAN.pdf

31. Ministério da Saúde (BR), Secretaria de Atenção à Saúde, Departamento de Atenção Básica. Guia alimentar para a população brasileira [Internet]. Brasília: Ministério da Saúde; 2014 [acesso em 2019 dez 22]. Disponível em: http://bvsms.saude.gov.br/bvs/publicacoes/guia_alimentar_populacao_brasileira_2ed.pdf

32. Silva IMG. Promoção de hábitos alimentares saudáveis no ambiente escolar: fortalecimento das ações de educação alimentar e nutricional e do programa de alimentação escolar [trabalho de conclusão de curso] [Internet]. Vitória de Santo Antão: Universidade Federal de Pernambuco; 2018 [acesso em 2020 Maio 20]. Disponível em: https://repositorio.ufpe.br/handle/123456789/23919

33. Souza SMFC, Lima KC, Alves MSCF. A rotulagem nutricional para escolhas alimentares mais saudáveis: estudo de intervenção, Natal-RN. Rev. Vigil Sanit Debate [Internet]. 2014 [acesso em: 2020 Maio 20];2(1):648. Disponível em: https://visaemdebate.incqs.fiocruz.br/index.php/visaemdebate/article/view/102

34. Marins BR, Jacob SC, Peres F. Avaliação qualitativa do hábito de leitura e entendimento: recepção das informações de produtos alimentícios. Ciênc Tecnol Aliment Campinas [Internet]. 2008 [acesso em 2020 Jan 20];28(3):579-85. Disponível em: https://www.scielo.br/scielo.php?pid=S010120612008000300012\&script=sci_arttext

35. Pelly FE, Thurecht R. Evaluation of athletes' food choices during Competition with Use of Digital Images. Nutrients [Internet]. 2019 [Acesso em 2020 Maio 20];11(7):1627. Disponível em: https://www.mdpi.com/2072$6643 / 11 / 7 / 1627 / \mathrm{htm}$ 
36. Burkhart SJ, Pelly FE. Dietary intake of athletes seeking nutrition advice at a major international competition. Nutrients [Internet]. 2016 [acesso em 2020 Maio 20];8(10):638. Disponível em: https://www.mdpi.com/2072$6643 / 8 / 10 / 638 / \mathrm{htm}$

37. Philippi ST. Pirâmide dos alimentos: fundamentos básicos da nutrição. Barueri: Manole; 2008.

38. Lustosa VM, Araújo FKC, Morais HMS, Sampaio FA. Nível de conhecimento e desidratação de jogadores juniores de futebol. Rev Bras Med Esporte [Internet]. 2017 [acesso em 2019 Jun 06];23(3):204-07. Disponível em: https://www.scielo.br/scielo.php?pid=S1517-86922017000300204\&script=sci_abstract\&tlng=es

39. Fortes LS, Nascimento-Júnior JRA, Mortatti AL, Lima-Júnior DRAA, Ferreira MEC. Effect of dehydration on passing decision making in soccer athletes. Res Q Exerc Sport [Internet]. 2018 [acesso em 2019 Jul 15];89(3):332-39 Disponível em: https://shapeamerica.tandfonline.com/doi/full/10.1080/02701367.2018.14880 26? scroll=top\&needAccess=true\#.XsW5zkRKjlU

40. Drumond MG, Carvalho FR, Guimarães EMA. Hidratação em atletas adolescentes: hábitos e nível de conhecimento. Rev Bras Nutr Sport [Internet]. 2007 [acesso em 2019 Dez 06];1(2):76-3. Disponível em: http:// www.rbne.com.br/index.php/rbne/article/view/20

41. Organização Mundial da Saúde. Diretriz: ingestão de açúcares para adultos e crianças [Internet]. Genebra: Organização Mundial da Saúde; 2015 [acesso em 2020 Jan 2]. Disponível em: http://www.who.int/nutrition/ publications/guidelines/sugars_intake/en/

42. Sociedade Brasileira de Pediatria, Departamento Científico de Nutrologia. Obesidade na infância e adolescência: manual de orientação [Internet]. $3^{\mathrm{a}}$ ed. São Paulo: SBP; 2019 [acesso em 2020 Ago 16]. Disponível em: https://www.sbp.com.br/fileadmin/user_upload/Manual_de_Obesidade_-_3a_Ed_web_ compressed.pdf

43. Cunha CML, Miraglia F. O impacto da educação alimentar sobre o consumo de açúcar em alunos de escola pública da região metropolitana de Porto Alegre. Cinergis [Internet]. 2017 [acesso em 2020 Maio 20];18(4):290-5. Disponível em: https://online.unisc.br/seer/index.php/cinergis/article/view/10436

\author{
Endereço para correspondência: \\ Ana Angélica Romeiro Cardoso \\ Centro Universitário Estácio do Ceará \\ Rua Eliseu Uchôa Beco, 600 \\ Bairro: Água Fria \\ CEP: $60810-270$ - Fortaleza - CE - Brasil \\ E-mail: anaromeirocardoso@gmail.com
}

Como citar: Cardoso AAR, Lima MRS, Campos MOC, Teixeira ECA, Pinheiro JSR. Educação em saúde no esporte com crianças e jovens em condição de vulnerabilidade social. Rev Bras Promoç Saúde. 2021;34:10960. 